\title{
Respiratory disease in pregnancy
}

\author{
M. DE SWIET \\ M.D., M.R.C.P. \\ Queen Charlotte's Hospital, Goldhawk Road, London, W.5, and the Department of Paediatrics, \\ Cardiothoracic Institute, Brompton Hospital, London SW3 6HP
}

\begin{abstract}
Summary
Respiratory disorders seem to be better tolerated during pregnancy than disorders of the cardiovascular system. Pregnancy seems to have a variable effect on bronchial asthma although respiratory function in general shows little change. Similarly patients with bronchiectasis do not tend to show functional deterioration. Fetal growth, however, may be adversely affected in these conditions if arterial hypoxaemia is present. The problems of drug treatment of respiratory disorders in pregnancy, particularly asthma and tuberculosis, are discussed.
\end{abstract}

\section{Introduction}

Pregnancy stresses the respiratory system remarkably little compared to its effect on the cardiovascular system. During pregnancy the minute ventilation increases by about $40 \%$ from $7.5 \mathrm{l} / \mathrm{min}$ to 10.5 $1 /$ min and oxygen consumption increases by about $15 \%$ from $30 \mathrm{ml} / \mathrm{min}$ to $40 \mathrm{ml} / \mathrm{min}$ (Hytten and Leitch, 1971). Yet in exercise, minute ventilation may increase to $80 \mathrm{l} / \mathrm{min}$ (Comroe et al., 1962), a tenfold or $1000 \%$ increase. Cardiac output also rises by approximately $40 \%$ from 4.5 to 6 litres $/ \mathrm{min}$ in pregnancy (Hytten and Leitch, 1971) but, in contrast, the maximum cardiac output achieved in exercise is no greater than 12 litres/min, an increase of threefold or $300 \%$. Thus, although cardiac output and minute ventilation increase by approximately $40 \%$ each in pregnancy the increase in cardiac output represents a far greater proportion of the maximum that the body is capable of than does the increase in ventilation. This is one reason why patients with respiratory disease are much less likely to deteriorate in pregnancy than those with cardiac disease. Also, now that tuberculosis has become uncommon, most patients with chronic respiratory disease such as bronchitis, are only seriously affected after the childbearing years in contrast to those with rheumatic or congenital heart disease. An exception is that patients with respiratory involvement due to poliomyelitis may still deteriorate in pregnancy (Woollam and Houlton, 1976). Nevertheless, patients with respiratory disease do pose some problems in pregnancy even though these may not be easily explicable on physiological grounds.

\section{Bronchial asthma}

The prevalence of active asthma in females aged 15 to 44 years in Great Britain is approximately $0.7 \%$ and perhaps twice as many give a history of asthma in the past (Williams, 1959). Asthma is therefore a relatively common complication of pregnancy occurring approximately as frequently as twin pregnancy yet in contrast to the very detailed knowledge of the outcome of twin pregnancy there is surprising confusion concerning the interrelationship of pregnancy and asthma. For example, Gordon et al. (1970) found that pregnancy made asthma worse, Schaefer and Silverman (1961) found that pregnancy had no effect on asthma, and Hiddlestone (1964) found that asthma improved in pregnancy. With regard to the fetus, Gordon et al. (1970) found no change in birth weight, but twice the perinatal mortality in the infants of mothers with asthma compared to controls. Bahna and Bjerkedal (1972) found that mothers with asthma produced smaller infants but these mothers had a high incidence of prematurity and hypertension. In the author's own study (Sims, Chamberlain and de Swiet, 1976) no change was found in simple respiratory function tests $\left(\mathrm{FEV}_{1} / \mathrm{FVC}\right.$ and $\left.\mathrm{FVC}\right)$ between pregnancy and the non-pregnant state in 27 patients with asthma, and 11 controls. This might be expected, since previous studies of $\mathrm{FEV}_{1}$ (e.g. Cugell et al., 1953; Rubin, Russo and Goucher, 1956; Milne, et al., 1977) have shown no change in $\mathrm{FEV}_{1}$ between pregnancy and the non-pregnant state. In addition, Milne et al. (1977) specifically measured the conductance of large airways in pregnancy and again found no change between pregnancy and the non-pregnant state in normal subjects. It is possible that normal subjects show some increase in vital capacity in pregnancy (Hytten and Leitch, 1971) but the present author and his colleagues certainly did not observe this in patients with asthma or in the controls that they studied (Sims et al., 1976). It is likely that the spontaneous fluctuations due to the natural history of asthma are far greater than any small changes which may occur in respiratory function during pregnancy. In that small series, it was not possible to detect any change in perinatal mortality or Apgar score associated with asthma, although the infants 
of mothers who were symptomatic from asthma during pregnancy were $170 \mathrm{~g}$ lighter than controls. When birth weight was corrected for maturity, sex, maternal height and parity (Thomson, Billewicz and Hytten, 1968) the mean birth weight of the patients with asthma was on the 42nd centile compared to the 62 nd centile for controls which just failed conventional significance testing ( $P=0 \cdot 06$, Student's $t$-test).

The management of patients with asthma should not vary simply because the patients are pregnant. The drugs used are aminophylline and other theophyllines, $\beta$-sympathomimetics, disodium cromoglycate and steroids, both orally and inhaled. There is no absolute contra-indication to any of these drugs in pregnancy. The $\beta$-sympathomimetics have been extensively used in premature labour and show little effect on the fetus. In theory, they might be thought to delay the onset of normal labour but this has not been the case in the author's experience when these drugs have been used for the treatment of asthma. There is no evidence that aminophylline or disodium cromoglycate are teratogenic. It has been suggested that corticosteroids cause cleft palate in the fetus (Francis and Smellie, 1964) but this risk has been over-emphasized and these life-saving drugs should not be withheld simply because the patient is pregnant. Inhaled steroids such as beclomethasone are almost entirely localized in the lungs (Harris, 1975) and very helpful in pregnancy (Morrow, Brown and Storey, 1975). Labour is very rarely complicated by attacks of asthma; if this should occur the patient should be treated with parenteral hydrocortisone in addition to inhaled $\beta$-sympathomimetics. Patients who have received oral steroids within the past year may have suppression of the pituitary adrenal system and the stress of the labour should be covered with hydrocortisone, say $100 \mathrm{mg}$ i.m. 6-hourly. The incidence of Addisonian collapse in labour, however, is exceedingly rare. Status asthmaticus carries rather a high maternal mortality in pregnancy. In one study (Gordon et al., 1970), the maternal mortality was $2 \%$ (6 deaths of 277 patients with asthma). This could be chiefly because the patients first come under the care of obstetricians rather than respiratory physicians and are not treated aggressively enough. It is well known that both patients and their attendants tend to underestimate the severity of attacks of status asthmaticus (MacDonald et al., 1976).

\section{Bronchiectasis}

There is a little recent information on the interrelationship of pregnancy and bronchiecstasis. Howie and Milne (1978) studied 3 patients and found no change in respiratory function during pregnancy which produced a normally grown fetus in each case. Templeton (1977) studied 2 pregnancies in one patient and found that each was associated with a growth-retarded fetus. It was suggested that this was due to maternal hypoxia which might also be the mechanism for the growth retardation that has been noted in patients with symptomatic asthma in pregnancy (Sims et al., 1976).

\section{Chronic bronchitis}

Chronic bronchitis rarely presents a problem in pregnancy because it is not present in patients during their reproductive period. It is most serious when associated with pulmonary hypertension and in these circumstances pregnancy may cause a very rapid deterioration in patients with cor pulmonale (G. Sutton, personal communication). It is presumed that because of the rise in pulmonary vascular resistance, pulmonary blood flow cannot increase to accommodate the increase in cardiac output normally associated with pregnancy and the patients may become more cyanosed with subsequent myocardial hypoxia and a further decline in cardiac output. Patients with pulmonary hypertension due to chronic bronchitis may therefore require termination of pregnancy in the same way as those with pulmonary hypertension associated with congenital heart disease (Morgan Jones and Howitt, 1965).

\section{Tuberculosis}

Pulmonary tuberculosis is fortunately now a rare complication of pregnancy. Although patients used to deteriorate very rapidly in the puerperium, this is now not so, and de March (1975) was unable to find any deleterious effect of pregnancy in 100 patients with tuberculosis who had been pregnant compared to 108 patients with pulmonary tuberculosis who had not been pregnant. The problems in the management of tuberculosis depend on which drugs might be used safely in pregnancy. Streptomycin causes damage to the vestibular and auditory parts of the eighth cranial nerve but when Conway and Birt (1965) studied 18 children whose mothers had been treated with streptomycin throughout pregnancy they found no clinical evidence of such damage and only evidence of minor damage on laboratory testing. PAS has the disadvantages that it is bulky and difficult to swallow, may cause gastrointestinal side effects and is not particularly potent as an antituberculous drug; but none of these problems is specific to pregnancy. Isoniazid is a potent antituberculous drug and may cause peripheral neuritis. However, its use has been studied extensively in pregnancy by Hammond, Selikoff and Robitzek (1967) who found no increase in perinatal mortality in 677 pregnancies. Ethambutol has come to replace PAS and although it may cause retrobulbar neuritis (Citron, 1969) there is no evidence that this occurs in abortion specimens 
(Lewitt et al., 1974) or infants that were subsequently delivered (Brobowitz, 1974). The drug of first choice for the treatment of tuberculosis appears to be rifampicin. However, it is teratogenic in mice and so at present cannot be recommended in the early stages of pregnancy. Nevertheless, there are unpublished series of patients who have been given rifampicin throughout pregnancy without any evidence of teratogenicity and this risk has probably been over-emphasized.

If the patient's organism is sensitive to isoniazid the neonate should be given isoniazid to prevent cross-infection from the mother and isoniazidresistant B.C.G. to acquire immunity to the organism (Gaisford and Griffiths, 1961). If the mother's organism is resistant to isoniazid the mother and infant must be separated until the child has become Mantoux positive in those cases where the mother is considered to be infective.

\section{Pneumonia}

Now that modern antibiotic drugs are available the maternal risk of bacterial pneumonia in pregnancy is trivial. The risks are to the fetus where the associated high fever and toxicity may cause abortion in the early stages of pregnancy or premature labour later on in pregnancy. Fever should therefore be treated aggressively with antipyretics and tepid sponging as necessary. In contrast, viral pneumonias may be associated with a high maternal mortality. These are usually only seen in the influenza epidemics such as those of 1918 and 1958. In these circumstances, $50 \%$ of the deaths in women of childbearing age may be associated with pregnancy (Freeman and Barno, 1959; Greenberg et al., 1958) and, during an episode of Asian influenza, pneumonia was the commonest cause of maternal mortality (Freeman, and Barno, 1959). Since 1958, the outbreaks of influenza have been less virulent and subsequent studies have not shown an increased maternal mortality (Editorial, 1976).

\section{Miscellaneous diseases}

Kyphoscoliosis is rarely a problem in pregnancy. The author and his colleagues have successfully delivered patients of normal children when the patients' vital capacities were less than $1000 \mathrm{ml}$. The most serious difficulty has been the induction of an epidural anaesthetic because of the distorted anatomy of the epidural space. Patients with fibrocystic disease rarely survive to child-bearing age. One such patient has recently been cared for who showed no evidence of deterioration during pregnancy and who had a normal live infant.

\section{Anaesthetic pulmonary complications}

The most recent confidential mortality report
(Department of Health and Social Security, 1975) showed that in England and Wales, 37 deaths were caused by the inhalation of stomach contents. Clearly these complications are best avoided. They are associated with pulmonary collapse due to inhalation of large particles and this should be treated by removal under bronchoscopy and bronchial lavage. There is also associated severe bronchospasm which may require treatment with antibiotics, corticosteroids and diuretics. The patients are severely ill and frequently require mechanical ventilation. It should always be remembered that inhalation of stomach contents, which is probably the most common respiratory cause of maternal mortality, is almost always avoidable.

\section{References}

Bahna, S.L. \& Bjerkedal, T. (1972) The course and outcome of pregnancy in women with bronchial asthma. Acta allergologica, 27, 397.

Brobowitz, I.D. (1974) Ethambutol in pregnancy. Chest, 66, 20.

Citron, K.M. (1969) Ethambutol: a review with special reference to ocular toxicity. Tubercle (Suppl.), 32,

Comroe, J.H., Forster, R.E., Dubois, A.B., Briscoe, W.A. \& Carlsen, E. (1962) The Lung, 2nd edn. p. 21. Year Book Publications, Chicago.

CONWAY, N. \& BIRT, B.D. (1965) Streptomycin in pregnancy: effect on the fetal ear. British Medical Journal, 2, 260.

Cugell, D.W., Frank, N.R., Gaensler, E.A. \& Badger, T.L. (1953) Pulmonary function in pregnancy. I. Serial observations in normal women. American Review of Tuberculosis, 67, 568.

De March, P. (1975) Tuberculosis and pregnancy. Five- to ten-year review of 215 patients in their fertile age. Chest, $68,800$.

Department of Health and Social Security (1975) Report on Confidential Enquiries into Maternal Deaths in England and Wales 1970-1972. H.M. Stationery Office, London.

EdITORIAL (1976) Pregnant patients and swine flu vaccine. Contemporary Obstetrics and Gynecology, 8, 74.

Francis, H.H. \& Smellie, J. (1964) General diseases in pregnancy - 1. British Medical Journal, 1, 887.

Freeman, D.W. \& Barno, A. (1959) Deaths from Asian influenza associated with pregnancy. American Journal of Obstetrics and Gynecology, 78, 1172.

GAISFORD, W. \& GRIFFITHS, M.I. (1961) A freeze-dried vaccine from isoniazid-resistant B.C.G. British Medical Journal, 1, 1500.

Gordon, M., Niswander, K.R., Berendes, H. \& Kantor, A.G. (1970) Fetal morbidity following potentially anoxigenic obstetric conditions. VII. Bronchial asthma American Journal of Obstetrics and Gynecology, 106, 421.

Greenberg, M., Jacobziner, H., Pakter, J. \& Weisel, B.A.G. (1958) Maternal mortality in the epidemic of Asian influenza, New York City, 1957. American Journal of Obstetrics and Gynecology, 76, 897.

Hammond, E.C., Selikoff, I.J. \& Robitzek, E.H. (1967). Isoniazid therapy in relation to later occurrence of cancer in adults and infants. British Medical Journal, 2, 792.

HaRRIS, D.M. (1975) Some properties of beclomethasone diproprionate and related steroids in man. Postgraduate Medical Journal, 51 (Suppl. 4), 20.

Hiddlestone, H.J.H. (1964) Bronchial asthma and pregnancy. New Zealand Medical Journal, 63, 521. 
Howie, A.D. \& MiLne, J.A. (1978) Pregnancy in patients with bronchiectasis. British Journal of Obstetrics and Gynaecology, 85, 197.

Hytten, F.E. \& LeItch, I. (1971) The Physiology of Human Pregnancy, 2nd edn, ch. 3. Blackwell Scientific Publications, Oxford.

Lewitt, T., Nebel, L., Terracina, S. \& Karman, S. (1974) Ethambutol in pregnancy: observations on embryogenesis. Chest, 66, 25.

MacDonald, J.B., MacDonald, E.T., Seaton, A. \& Williams, D.A. (1976) Asthma deaths in Cardiff 1963-74; 53 deaths in hospital. British Medical Journal, 2, 721.

Milne, J.A., Mills, R.J., Howie, A.D. \& PACK, A.I. (1977) Large airways function during normal pregnancy. British Journal of Obstetrics and Gynaecology, 84, 448.

Morgan Jones, A. \& HowitT, G. (1965) Eisenmenger syndrome in pregnancy. British Medical Journal, 1, 1627.

Morrow Brown, H. \& StOREY, G. (1975) Treatment of allergy of the respiratory tract with beclomethasone diproprionate steroid aerosol. Postgraduate Medical Journal, 51 (Supp. 4), 59.
Rubin, A., Russo, N. \& Goucher, D. (1956) The effect of pregnancy upon pulmonary function in normal women. American Journal of Obstetrics and Gynecology, 72, 963.

Schaefer, G. \& Silverman, F. (1961) Pregnancy complicated by asthma. American Journal of Obstetrics and Gynecology, 82, 182

Sims, C.D., Chamberlain, G.V.P. \& de Swiet, M. (1976) Lung function test in bronchial asthma during and after pregnancy. British Journal of Obstetrics and Gynaecology, 83, 434.

Templeton, A. (1977) Intrauterine grown retardation associated with hypoxia due to bronchiectasis. British Journal of Obstetrics and Gynaecology, 84, 389.

Thomson, A.M., Billewicz, W.Z. \& Hytten, F.E. (1968) The assessment of fetal growth. Journal of Obstetrics and Gynaecology of the British Commonwealth, 75, 903.

Williams, D.A. (1959) Definition, prevalence, predisposing and contributory factors. In: International Textbook of Allergy (Ed. by Jamar, J.M.). Blackwell Scientific Publications, Oxford.

Woollam, C.H.M. \& Houlton, M.C.C. (1976) Respiratory failure in pregnancy. Anaesthesia, 31, 1217. 